grinding kinetics and is independent of the conventional Bond Work Index method.

\section{Nomenclature}

$=$ mill diameter

$d_{m} \quad=$ diameter of grinding media

$F \quad=$ feed

$f \quad=$ frequency of force application

$g \quad=$ acceleration due to gravity

$g_{c} \quad=$ gravity conversion factor

$=$ filling degree of grinding media

$=$ rate constant

$=$ strength factor

$=$ mill length

$=$ constant

$=$ number of grinding media

$=$ magnitude of force

$=$ selection function

$=$ volumetric ratio of bulk powder to interstice of media

$=$ volumetric ratio of bulk powder when

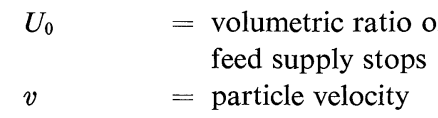

$W \quad$ hold-up
$=$ characteristic size $[\mu]$

$\varepsilon \quad=$ porosity $\quad[-]$

$\phi \quad=$ fractional opening area on the screen plate [-]

$\rho_{a} \quad=$ bulk density of particles $\quad\left[\mathrm{kg} / \mathrm{m}^{3}\right]$

$\rho_{m} \quad=$ density of grinding media $\quad\left[\mathrm{kg} / \mathrm{m}^{3}\right]$

$\sigma \quad=$ strength $\quad\left[\mathrm{Kg} / \mathrm{m}^{2}\right]$

\section{Literature Cited}

1) Bond, F. C.: Min. Eng., 4, 484 (1952)

2) Cement Eng. Assoc. Japan: "Report of Grinding Committee", S-4 (1963)

3) Chūjo, K.: Kagaku Kōgaku to Kagaku Kikai, 7, 1 (1949)

4) Furuya, M., Y. Nakajima, and T. Tanaka.: I \& EC Proc. Des. Develop., 10, 449 (1971)

5) Hayashi, M. and T. Tanaka.: J. Chem. Eng. Japan, 5, 308 (1972)

6) Knudsen, F. P.: J. Am. Ceram. Soc., 42, 376 (1959)

7) Rose, H. E. and R. E. Sullivan.: "Ball, Tube, Rod Mills" Constable, London (1958)

8) Tanaka, T. and S. Kawai.: Aufbereit, Tech., 4, 282 (1963)

9) Tanaka, T.: J. Chem. Eng. Japan, 5, 310 (1972)

10) Tanaka, T.: ibid., 5, 425 (1972)

\title{
DECOUPLING FEEDBACK CONTROL OF A BINARY DISTILLATION COLUMN*
}

\author{
EIJI NAKANISHI, HiroAKI YASUOKA AND EIICHI KUNUGITA** \\ Department of Chemical Engineering, Kobe University, Kobe
}

A convenient technique for decoupling feedback control synthesis of binary distillation columns is presented. The control system is analyzed by digital simulation based on the plant dynamics given by Wood et al..$^{5,6)}$. The computational results demonstrate the applicability of the technique proposed in this study.

\section{Decoupling Condition and Controller Synthesis}

In order that the decoupling condition is satisfied for a multi-variable feedback control system, each element of the setpoint vector must affect only the corresponding element of the state vector. This is possible if and only if the matrix

$$
\left(\boldsymbol{I}+\boldsymbol{G}^{p} \boldsymbol{G}^{u} \boldsymbol{G}^{c} \boldsymbol{G}^{m}\right)^{-1} \boldsymbol{G}^{p} \boldsymbol{G}^{u} \boldsymbol{G}^{c}
$$

is diagonal ${ }^{4}$, where $\boldsymbol{I}$ is the unit matrix, and $\boldsymbol{G}^{p}$,

\footnotetext{
* Received on May 4, 1974

Presented at the 39th Annual Meeting of The Soc. of Chem.

Engrs., Japan, at Kobe, April 2, 1974

** Department of Chemical Engineering, Osaka University, Toyonaka, Osaka, Japan

二657 神戸市灘区六甲台町

神戸大学工学部化学工学科 中西英二
}

$\boldsymbol{G}^{u}, \boldsymbol{G}^{c}, \boldsymbol{G}^{m}$ are the matrix transfer functions of plant, final control element, controller, and measuring element, respectively. A two-variable system in which both $\boldsymbol{G}^{u}$ and $\boldsymbol{G}^{m}$ are assumed to be diagonal is considered. When $\boldsymbol{G}^{m}$ is diagonal, the decoupling condition will be achieved if the matrix $\boldsymbol{G}^{p} \boldsymbol{G}^{u} \boldsymbol{G}^{c}$ is diagonal.

The feedback control system in which $\boldsymbol{G}^{c}$ is represented as shown in Fig. $\mathbf{1}$ is referred to as "simplified decoupling"1). On the other hand, the matrix transfer function $\boldsymbol{G}^{c}$ is expressed as the following relation by using the decoupling condition that the matrix $\boldsymbol{G}^{p} \boldsymbol{G}^{u} \boldsymbol{G}^{c}$ must be diagonal.

$$
\boldsymbol{G}^{c}=\left[\begin{array}{cc}
1 & -\frac{g_{12}^{p} g_{22}^{u}}{g_{11}^{p} g_{11}^{u}} \\
-\frac{g_{21}^{p} g_{11}^{u}}{g_{22}^{p} g_{22}^{u}} & 1
\end{array}\right]\left[\begin{array}{cc}
g_{11}^{c} & 0 \\
0 & g_{22}^{c}
\end{array}\right]
$$

This relation indicates that the original feedback control system is identical to a "simplified decoupling" whenever the decoupling condition is satisfied and if the decoupling compensator is designed by the follow- 


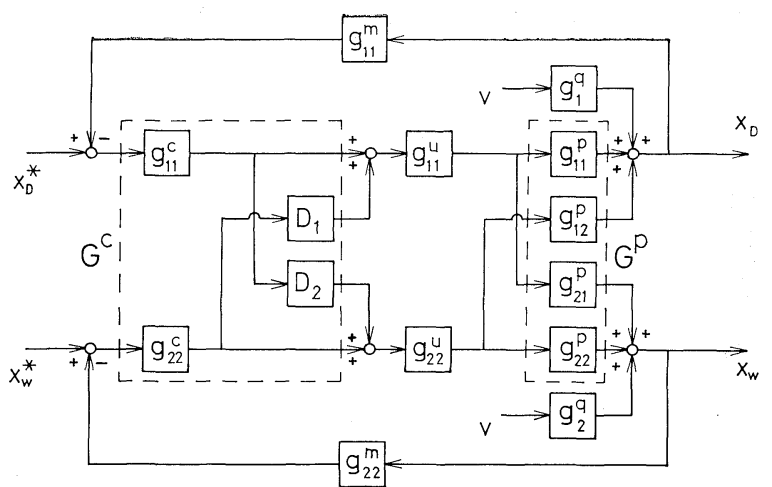

Fig. 1 Block diagram of two-variable "simplified decoupling" feedback control system with single disturbance variable

Table 1 Parameters of the transfer function $G^{p}$ expressed by Eq. (4)

\begin{tabular}{cccccccc}
$j$ & \multicolumn{2}{c}{$K_{i j}$} & \multicolumn{2}{c}{$T_{i j}$} & \multicolumn{2}{c}{$\tau_{i j}$} \\
$i$ & 1 & 2 & 1 & 2 & 1 & 2 \\
\hline 1 & 28.2 & -41.7 & 16.7 & 21.0 & 1.0 & 3.0 \\
2 & 14.6 & -42.8 & 10.9 & 14.4 & 7.0 & 3.0 \\
\hline
\end{tabular}

ing equations.

$$
D_{1}=-\frac{g_{12}^{p} g_{22}^{u}}{g_{11}^{p} g_{11}^{u}}, \quad D_{2}=-\frac{g_{21}^{p} g_{11}^{u}}{g_{22}^{p} g_{22}^{u}}
$$

For the decoupling feedback control system to be useful in practice, it is necessary not only that the resulting decoupling control system be stable but that the transfer functions of compensator should be physically realizable.

From the assumption that both $\boldsymbol{G}^{u}$ and $\boldsymbol{G}^{m}$ are diagonal, it can be seen that the resulting decoupling feedback control system is equivalent to a pair of single-variable feedback control systems in which the loop transfer functions are given by the following equations.

$$
\begin{aligned}
& g_{1}^{\text {loop }}=\frac{g_{11}^{p} g_{22}^{p}-g_{12}^{p} g_{21}^{p}}{g_{22}^{p}} g_{11}^{u} g_{11}^{c} g_{11}^{m} \\
& g_{2}^{\text {loop }}=\frac{g_{11}^{p} g_{22}^{p}-g_{12}^{p} g_{21}^{p}}{g_{11}^{p}} g_{22}^{u} g_{22}^{c} g_{22}^{m}
\end{aligned}
$$

The design procedure presented in this paper is to first determine the transfer functions of compensator, $D_{1}, D_{2}$, based on Eq. (2) and then to synthesize the transfer functions of diagonal elements of controller, $\boldsymbol{G}^{c}$. The Ziegler-Nichols criterion is applied to synthesizing the transfer functions $g_{11}^{c}, g_{22}^{c}$ separately for each single-variable feedback control system with the loop transfer functions given by Eq. (3).

\section{Digital Simulation and Numerical Results}

The recent work by Wood et al. ${ }^{5,6)}$ shows that the dynamics of a pilot-scale distillation column of 9 inch diameter and 8 bubble-cap trays equipped with a total condenser and a basket-type reboiler, in which the binary system of methanol and water is processed, is identified by the following relation.

$$
\left[\begin{array}{l}
\mathbf{L}\left(\Delta x_{D}\right) \\
\mathbf{L}\left(\Delta x_{W}\right)
\end{array}\right]=\boldsymbol{G}^{p}\left[\begin{array}{l}
\mathbf{L}(\Delta R) \\
\mathbf{L}(\Delta V)
\end{array}\right], g_{i j}^{p}=\frac{K_{i j} e^{-\tau i j s}}{1+T_{i j} s}, i, j=1,2
$$

The parameters appearing in Eq. (4) are summarized in Table 1. When there is no lag in the final control element, Eq. (2) is rewritten as

$$
\begin{aligned}
& D_{1}=-\frac{K_{12} U_{2}}{K_{11} U_{1}} \cdot \frac{1+T_{11} s}{1+T_{12} S} e^{-\left(\tau_{12}-\tau_{11}\right) s} \\
& D_{2}=-\frac{K_{21} U_{1}}{K_{22} U_{2}} \cdot \frac{1+T_{22} S}{1+T_{21} S} e^{-\left(\tau_{21}-\tau_{22}\right) s}
\end{aligned}
$$

where $U_{1}, U_{2}$ are the constant diagonal elements of $G^{u}$. The compensator with the transfer functions given by Eq. (5) is realizable since the conditions of $\tau_{12}>\tau_{11}$ and $\tau_{21}>\tau_{22}$ are satisfied.

Since the transfer functions of plant, final control element, and measuring element, $\boldsymbol{G}^{p}, \boldsymbol{G}^{u}$, and $\boldsymbol{G}^{m}$ are prescribed and the transfer functions of compensator, $D_{1}, D_{2}$ are determined by Eq. (5), the decision on the diagonal elements of $\boldsymbol{G}^{c}, \boldsymbol{g}_{11}^{c}, g_{22}^{c}$, remains to be made before entering the digital simulation analysis of the two-variable feedback control system as shown in Fig. 1. As explained in the previous section, $g_{11}^{c}, g_{22}^{c}$ are synthesized by separately applying the Ziegler-Nichols criterion to each single-variable feedback control system, the loop transfer function of which is defined by Eq. (3). This method in determining $g_{11}^{c}, g_{22}^{c}$ is referred to as $\mathrm{ZN}$ method in the following digital simulation analysis. The digital simulation is carried out by using both IBM 360/65J CSMP and FACOM 230/60 ADSL simulators.

The control performance of the column for the negative nominal step change in setpoints of both overhead and bottom compositions is shown in Fig. 2, in which the label of RC method means that the feedback control system is designed so as to construct the ratio control system proposed by Rijnsdrop ${ }^{2,3)}$. In the feedback control system which is synthesized by the RC method, $g_{11}^{c}, g_{22}^{c}$ are devised to function as ratio controllers, while there is no decoupling compensator required. The conventional PI controllers are used for $g_{11}^{c}, g_{22}^{c}$.

In Fig. 2 it can be seen that the decoupling feedback control system designed by the $\mathrm{ZN}$ method results in a significant improvement in the control performances of both overhead and bottom compositions compared with the non-decoupling feedback control system synthesized by the RC method. In particular, the control performance of bottom composition is far inferior to that of overhead composi- 
tion in the non-decoupling feedback control system. This result corresponds to the fact that it is difficult in general to achieve close control of bottom composition with the ratio control system because this system ignores the effect of control action in the top loop on the bottom composition ${ }^{2,3,6)}$.

Wood and Berry $\left.{ }^{6}\right)$ have proposed a controller design method of decoupling feedback control system whereby the controller settings are adjusted to minimize the integral of absolute error of the state variable during the course of control. This method in determining $g_{11}^{c}, g_{22}^{c}$ is referred to as IAE method in this paper.

The control performances of overhead composition for both positive and negative nominal step changes in feed flow rate are studied for the purpose of investigating the applicabilities of $\mathrm{ZN}$ and IAE methods to the synthesis of decoupling feedback control system of binary distillation column. Again the conventional PI controllers are used for $g_{11}^{c}, g_{22}^{c}$. The following transfer functions obtained by Wood and $\mathrm{Pacey}^{5)}$ are used in the digital simulation analysis shown in Fig. 3.

$$
g_{1}^{q}=\frac{\mathbf{L}\left(\Delta x_{D}\right)}{\mathbf{L}(\Delta F)}= \begin{cases}\frac{10.8}{1+27 s} e^{-6 s} & \text { for increase in } F \\ \frac{15.0}{1+10 s} e^{-8 s} & \text { for decrease in } F\end{cases}
$$

It should be noticed that the difference between the performances of both noninteracting control systems is comparatively small, while the controller design by the $\mathrm{ZN}$ method is much easier than that by the IAE method.

\section{Nomenclature}

\begin{tabular}{|c|c|c|}
\hline$D_{i}$ & $=$ transfer function of compensator, $i=1$, & \\
\hline$F$ & $=$ feed flow rate & {$[\mathrm{kg} / \mathrm{min}]$} \\
\hline $\boldsymbol{G}$ & $=$ matrix transfer function & \\
\hline$g_{i j}$ & $=i j$-th element of $G, i, j=1,2$ & \\
\hline$g_{i}^{\text {loop }}$ & $=$ loop transfer function, $i=1,2$ & \\
\hline$g_{i}^{q}$ & $\begin{aligned}= & \text { transfer function relating state variable } \\
& \text { to disturbance variable, } i=1,2\end{aligned}$ & \\
\hline $\boldsymbol{I}$ & $=$ unit matrix & \\
\hline$K_{i j}$ & $=$ gain constant of $g_{i j}^{p}, i, j=1,2 \quad[\mathrm{wt} \%$ & $\cdot \min / \mathrm{kg}]$ \\
\hline $\mathbf{L}$ & $=$ operator of Laplace transformation & \\
\hline$M_{i}$ & $=$ constant for $g_{i i}^{m}, i=1,2$ & {$[-]$} \\
\hline$R$ & $=$ reflux rate & {$[\mathrm{kg} / \mathrm{min}]$} \\
\hline$s$ & $=$ parameter of Laplace transformation & {$\left[\min ^{-1}\right]$} \\
\hline$T_{i j}$ & $=$ time constant of $g_{i j}^{p}, i, j=1,2$ & [min] \\
\hline$U_{i}$ & $=$ constant for $g_{i i}^{u}, i=1,2$ & {$[\mathrm{~kg} / \mathrm{min}]$} \\
\hline$V$ & $=$ steam flow rate & {$[\mathrm{kg} / \mathrm{min}]$} \\
\hline$v$ & $=$ disturbance variable & \\
\hline$x_{D}$ & $=$ composition of overhead product & {$[\mathrm{wt} \%]$} \\
\hline$x_{W}$ & $=$ composition of bottom product & {$[\mathrm{wt} \%]$} \\
\hline$\Delta$ & $=$ perturbation from a steady-state con & tion \\
\hline$\tau_{i j}$ & $=$ pure delay time of $g_{i j}^{p}, i, j=1,2$ & [min] \\
\hline
\end{tabular}

$\langle$ Superscripts〉

$* \quad=$ setpoint of state variable

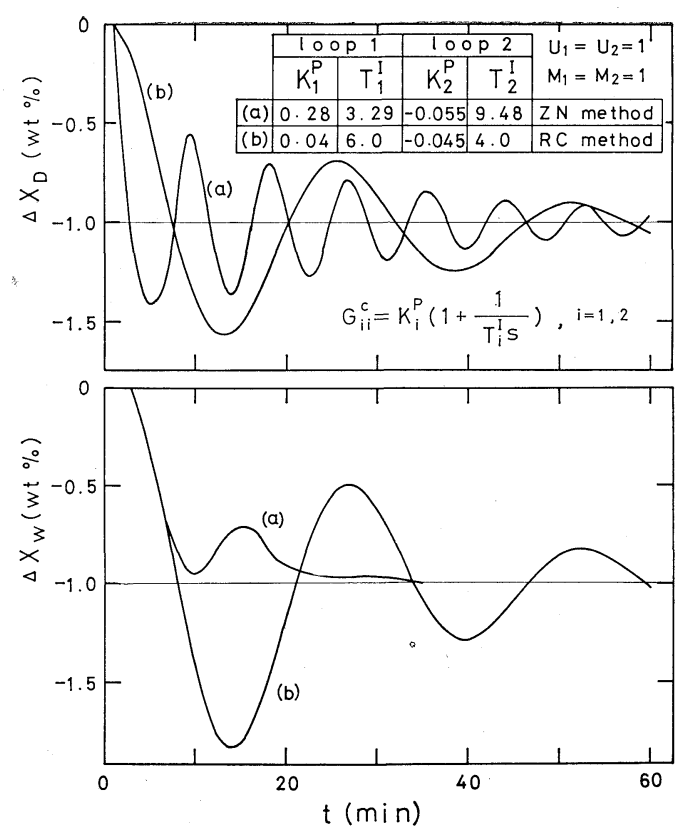

Fig. 2 Control performances of $x_{D}$ and $x_{W}$ for negative nominal step change in both setpoints

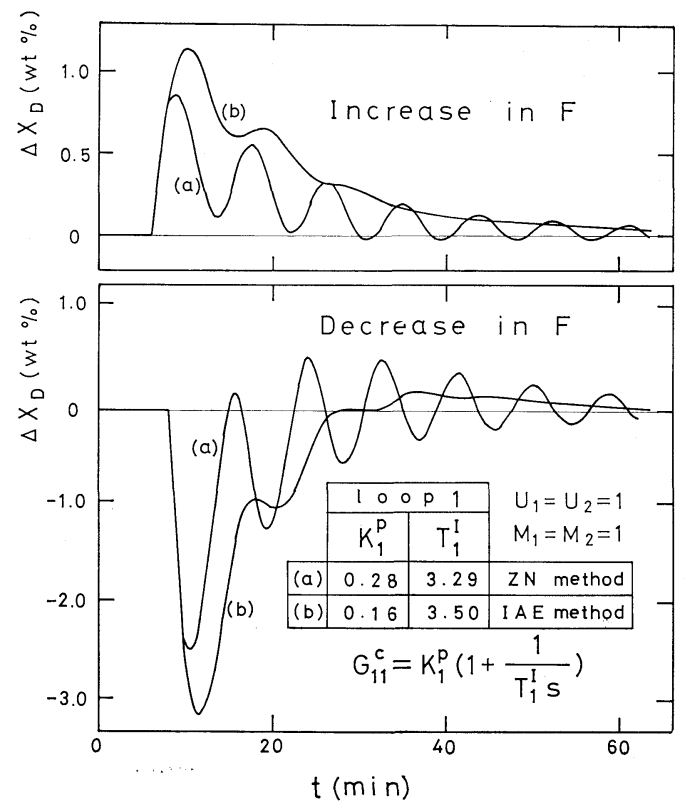

Fig. 3 Control performances of $x_{D}$ for both positive and negative nominal step changes in feed flow rate

$$
\begin{aligned}
c, m, p, u= & \text { controller, measuring element, plant, and final } \\
& \text { control element, respectively }
\end{aligned}
$$

\section{Literature Cited}

1) Luyben, W. L.: AIChE J., 16, 198 (1970)

2) Rijnsdorp, J. E.: Automatica, 3, 15 (1965)

3) idem: ibid., 3, 29 (1965)

4) Takahashi, Y., M. J. Rabins and D. M. Auslander: "Control and Dynamic Systems", Addison-Wesley Publishing Company, Inc. (1970)

5) Wood, R. K. and W. C. Pacey: Can. J. Chem. Eng., 50, 376 (1972)

6) Wood, R. K. and M. W. Berry: Chem. Eng. Sci., 28, 1707 (1973) 